\title{
Necessity of a repeat cholangiogram during biliary stent removal after postcholecystectomy bile leak
}

\author{
Vishal Jain $M D^{1}$, Nathan Yeasted MD ${ }^{1}$, Nakechand Pooran MD $^{2}$
}

V Jain, N Yeasted, N Pooran. Necessity of a repeat cholangiogram during biliary stent removal after postcholecystectomy bile leak. Can J Gastroenterol 2012;26(10):701-704.

PURPOSE: To assess the need for repeat endoscopic retrograde cholangiography (ERC) in patients undergoing biliary stent removal after management of postcholecystectomy bile leak.

METHODS: A retrospective analysis of the Clinical Outcomes Research Initiative endoscopy database at PennState Milton S Hershey Medical Center (Hershey, Pennsylvania, USA) identified all patients referred for ERC with an indication of postcholecystectomy bile leak from January 2001 to June 2010. Baseline demographics, location of bile leak, size of biliary stent placed, duration of stenting, bile leak persistence, and the presence of stone, sludge or strictures on repeat ERC were analyzed.

RESULTS: A total of 81 patients underwent ERC for management of bile leaks after cholecystectomy. One patient was excluded due to a complete transection of the common bile duct necessitating immediate surgical intervention. Fourteen $(17.5 \%)$ patients underwent open cholecystectomy, 46 (57.5\%) underwent laparoscopic procedures and 10 (12.5\%) procedures were converted from a laparoscopic to an open approach intraoperatively. Of the 80 patients, 47 (58.7\%) had a cystic duct leak, $11(13.7 \%)$ had a right hepatic duct leak, $11(13.7 \%)$ had a common bile duct leak, five $(6.2 \%)$ had a gallbladder fossa leak, four $(5 \%)$ had a common hepatic duct leak and the remaining two $(2.5 \%)$ had a left hepatic duct leak. All 80 patients underwent biliary stenting as part of management for their bile leak. Fifty-seven of the 80 patients $(71.2 \%)$ had a $10 \mathrm{Fr}$ stent placed, with the remainder undergoing placement of a $7 \mathrm{Fr}$ stent. Seventy-five $(93.7 \%)$ patients underwent biliary sphincterotomy during the initial ERC. Sixty-nine patients underwent repeat ERC after a mean duration of 8.2 weeks (range 0.4 to 18.5 weeks). Eleven patients had no reviewable records regarding a repeat procedure performed for stent removal. Three patients required an early repeat ERC due to suspicion of cholangitis and, hence, were excluded from the final analysis. Of the 66 patients included in the final analysis, 61 (92.4\%) had resolution of their bile leak on repeat ERC. All patients had resolution of their bile leak by the third ERC. Fifteen patients (22.7\%) had an abnormality on repeat cholangiography (persistent leak in four, stones in three, sludge in seven, and a combination of leak and stone in one) that required further endoscopic intervention including balloon sweep or additional stenting. CONCLUSION: Although the majority of postcholecystectomy bile leaks resolve after biliary stent placement, a sizeable percentage $(22.7 \%)$ of patients had abnormalities on subsequent cholangiograms that required further intervention. These findings suggest the need for a repeat $\mathrm{ERC}$ at the time of biliary stent removal in the management of postcholecystectomy bile leaks.

Key Words: Bile leak; Biliary stent; Endoscopic retrograde cholangiogram; ERCP; Postcholecystectomy

\author{
La nécessité de reprendre une cholangiographie \\ après le retrait d'une endoprothèse biliaire en \\ raison d'une fuite biliaire suivant une \\ cholécystectomie
}

\begin{abstract}
OBJECTIF : Évaluer la nécessité de reprendre une cholangiographie rétrograde endoscopique (CRE) chez des patients se faisant enlever une endoprothèse biliaire après la prise en charge d'une fuite biliaire suivant une cholécystectomie.
\end{abstract}

MÉTHODOLOGIE : Une analyse rétrospective de la base de données de l'initiative de recherche sur les issues cliniques du Milton S Hershey Medical Center à l'université Penn State, (Hershey, Pennsylvanie, États-Unis) a permis de repérer tous les patients aiguillés vers une CRE en raison d'une indication de fuite biliaire après une cholécystectomie entre janvier 2001 et juin 2010. Les auteurs ont analysé les données démographiques de base, le foyer de la fuite biliaire, la dimension de l'endoprothèse biliaire installée, la durée d'installation de l'endoprothèse, la persistance de la fuite biliaire et la présence de calcul, de boue ou de constriction à la reprise de la CRE.

RÉSULTATS : Au total, 81 patients ont subi une CRE pour la prise en charge des fuites biliaires après une cholécystectomie. Un patient a été exclu en raison d'une dissection complète du canal cholédoque nécessitant une intervention chirurgicale immédiate. Quatorze patients (17,5\%) ont subi une cholécystectomie ouverte, 46 (57,5\%), des interventions laparoscopiques, et dix $(12,5 \%)$, une conversion de la laparoscopie à une approche intraopératoire ouverte. Sur les 80 patients, $47(58,7 \%)$ avaient une fuite du canal kystique, $11(13,7 \%)$, une fuite du canal hépatique droit, 11 (13,7\%), une fuite du canal cholédoque, cinq $(6,2 \%)$, une fuite du lit de la vésicule biliaire, quatre (5\%), une fuite du canal hépatique et les deux derniers (2,5\%), une fuite du canal hépatique gauche. Les 80 patients ont tous reçu une endoprothèse biliaire dans le cadre de la prise en charge de leur fuite biliaire. Cinquante-sept des 80 patients $(71,2 \%)$ se sont fait installer une endoprothèse de calibre $10 \mathrm{Fr}$, et les autres, une endoprothèse de calibre $7 \mathrm{Fr}$. Soixante-quinze patients $(93,7 \%)$ ont subi une sphinctérotomie biliaire pendant la première CRE, et 69 , une reprise de la CRE au bout d'une durée moyenne de 8,2 semaines (plage de 0,4 à 18,5 semaines). Onze patients n'avaient pas de dossier à examiner au sujet d'une reprise de l'intervention en vue du retrait de l'endoprothèse. Trois patients ont dû subir une reprise rapide de la CRE en raison de présomptions de cholangite et ont donc été exclus de l'analyse définitive. Sur les 66 patients qui en ont fait partie, 61 (92,4 \%) présentaient une résolution de la fuite biliaire. Celle-ci était résolue chez tous les patients à la troisième CRE. Quinze patients $(22,7 \%)$ ont présenté une anomalie à la reprise de la cholangiographie (fuite persistante dans quatre cas, calculs dans trois, boue dans sept et association de fuite et de calcul dans un), laquelle a nécessité une intervention endoscopique plus complexe, incluant un balayage par ballonnet ou une nouvelle endoprothèse.

CONCLUSION : Même si la majorité des fuites biliaires après une cholécystectomie se résolvent grâce à l'installation d'une endoprothèse biliaire, un fort pourcentage des patients $(22,7 \%)$ présentaient des anomalies aux cholangiographies subséquentes, lesquelles exigeaient une intervention supplémentaire. Les observations indiquent la nécessité de reprendre la CRE au moment de l'extraction de l'endoprothèse biliaire pour la prise en charge des fuites biliaires après une cholécystectomie.

cholecystectomies performed laparoscopically has increased steadily since the introduction of this technique in the early 1990s. Initially, the laparoscopic approach was associated with an almost 10-fold increase in the incidence of bile duct injuries compared with open
$\mathrm{B}$ le leaks represent a serious and often challenging surgical complication. Bile duct injuries develop commonly as a result of cholecystectomy but can also be encountered during the course of surgery of the liver, pancreas, stomach or duodenum. The number of

${ }^{1}$ Division of Gastroenterology/Hepatology, PennState Milton S Hershey Medical Center, Hershey, Pennsylvania; ${ }^{2}$ Division of Gastroenterology/Hepatology, Robert Wood Johnson University Hospital, New Brunswick, New Jersey, USA

Correspondence: Dr Vishal Jain, 575 Jack Martin Boulevard, Brick, New Jersey 08724, USA. Telephone 732-840-2042, fax 732-840-3169, e-mail vjaingi@gmail.com

Received for publication April 4, 2012. Accepted April 18, 2012 


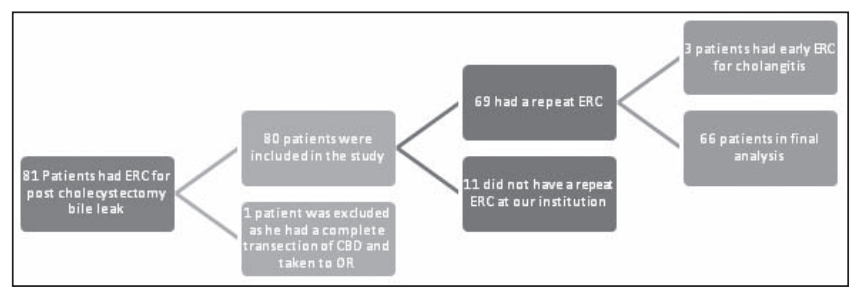

Figure 1) Schematic of subjects included in the study. CBD Common bile duct; ERC Endoscopic retrograde cholangiography; OR Operating room

cholecystectomy. Subsequently, large studies have shown that the incidence of bile duct injuries as a consequence of laparoscopic cholecystectomy has decreased as surgeons gained more experience with this approach. However, the incidence of iatrogenic biliary injury remains higher than in the open cholecystectomy era $(0.5 \%$ versus $0.2 \%)(1)$.

Postcholecystectomy bile leaks are most often managed using endoscopic retrograde cholangiography (ERC). Endoscopic management strategies include biliary sphincterotomy, biliary stent placement, nasobiliary tube placement or a combination of these methods (2). Nasobiliary tube placement is less often used because of patient discomfort and the possibility of premature dislodgement. Sandha et al (3) reported a success rate of $91 \%$ for patients who have a low-grade bile leak managed with biliary sphincterotomy alone. In the same series, comparable success rates were observed for patients with highgrade leaks who were managed using biliary stent placement with or without concomitant biliary sphincterotomy.

Once biliary stenting is undertaken in the management of postcholecystectomy bile leaks, no formal recommendations for follow-up evaluation exist, particularly regarding procedures performed for stent removal. Performing ERC with and without balloon sweeps adds procedure time, increases risk, and significantly raises costs compared with upper endoscopy and stent removal. It is unclear whether repeating ERC is necessary for all patients undergoing endoscopic removal of previously placed biliary stents in the management of postcholecystectomy bile leaks.

Standard practice at our institution for the management of postcholecystectomy bile leaks has been biliary stent placement with or without biliary sphincterotomy. We repeat ERC at the time of stent extraction, which is typically performed six to eight weeks after the initial procedure. The present analysis was undertaken to determine whether our current practice of repeating ERC at the time of biliary stent removal following clinical resolution of uncomplicated postcholecystectomy bile leaks is necessary. Secondarily, we aimed to identify characteristics that are associated with abnormalities found on repeat ERC.

\section{METHODS}

\section{Patients}

Potential candidates for the present retrospective case study were identified from the Clinical Outcomes Research Initiative (CORI) (Portland, Oregon, USA) database used in the endoscopy centre at the Penn State University, Milton S Hershey Medical Center (Hershey, Pennsylvania, USA). The database was queried to obtain a list of all patients who had undergone an ERC with postcholecystectomy bile leak listed as the primary preprocedure indication between January 2001 and June 2010. Only patients who had a postcholecystectomy bile leak definitively demonstrated on ERC were included in the study. Exclusion criteria included bile leaks secondary to liver lacerations or resection, trauma or as a complication of any procedure other than cholecystectomy. The present study was approved by the Institutional Review Board at the Penn State University Hershey Medical Center.

\section{Data abstraction}

CORI reports and the medical charts of eligible patients were reviewed and standardized data for each patient was collected including age, sex and type of cholecystectomy (open, laparoscopic, laparoscopic converted to open or unknown). Procedural details regarding the initial ERC included whether biliary sphincterotomy and/or biliary stenting was performed, size of the biliary stent placed and site of biliary leak identified. Data examined during the follow-up ERC performed for stent removal included the time interval from the initial procedure, whether the leak had resolved at the time of the repeat procedure, and the presence of common bile duct (CBD) stones or sludge.

\section{Statistical analysis}

Descriptive statistics were used in the present retrospective case series to describe characteristics of the patients, procedures and outcomes. Univariate logistical regression analysis was performed using SAS software (SAS Institute, USA).

\section{RESULTS}

A total of 81 patients underwent ERC for management of bile leaks after cholecystectomy at the Penn State University Hershey Medical Center between January 1, 2001, and June 30, 2010. One patient was excluded from the study due to a complete transection of the CBD and was taken to the operating room immediately for surgical repair. Of the 80 patients identified for inclusion in the present study, $11(13.7 \%)$ had no reviewable records regarding a repeat procedure performed for stent removal. This provided 69 patients who had a biliary stent placed during their ERC in the management of postcholecystectomy bile leaks who then underwent a repeat cholangiogram during stent removal per standard practice six to eight weeks after the initial procedure. Three additional patients were excluded because they underwent an early ERC performed due to concerns of cholangitis (Figure 1), leaving a total of 66 patients for final analysis.

The mean age of the patients was 53 years (range 13 to 97 years). Of the original 80 patients identified, $51(62.6 \%)$ were women and $29(36.2 \%)$ were men. Forty-six $(57.5 \%)$ of the 80 patients underwent a laparoscopic cholecystectomy, $14(17.5 \%)$ had an open cholecystectomy and $10(12.5 \%)$ had an initial laparoscopic approach that was converted to an open procedure during surgery. There was no documentation of the surgical approach in 10 patients $(12.5 \%)$. Forty-seven patients $(58.7 \%)$ were found to have a cystic duct stump leak, $11(13.7 \%)$ had a right hepatic duct leak, two (2.5\%) a left hepatic duct leak, four (5\%) a common hepatic duct leak, $11(13.7 \%)$ a CBD leak and five (6.2\%) had a leak noted in the gallbladder fossa without a clear source identified. The baseline characteristics of the original 80 patients identified for inclusion are summarized in Table 1 .

All 80 patients $(100 \%)$ had a biliary stent placed during their initial ERC; the most common stent was $10 \mathrm{Fr}$ (71.2\%). Seventy-five $(93.7 \%)$ patients also underwent biliary sphincterotomy during their initial ERC. Only 19 (23.7\%) patients had balloon sweeps performed during the initial ERC. The mean duration between the initial and repeat ERC was 8.2 weeks (range three to 130 days). Sixty-one of the 66 patients $(92.4 \%)$ included in the final analysis experienced resolution of their bile leak at the time of repeat ERC performed for stent removal and the remaining five patients experienced subsequent resolution of their bile leak during a third ERC. Fifteen patients $(22.7 \%)$ had an abnormality identified during repeat cholangiography. These abnormalities included persistent leaks in four, choledocholithiasis in three, sludge in seven, and a persistent leak and CBD stone in one. All 15 of these patients required additional interventions including balloon sweeps or subsequent stenting (Table 2).

A univariate analysis was performed examining abnormalities on follow-up ERC and variables including CBD stones at initial ERC, location of bile leak, type of cholecystectomy, biliary stricture on initial ERC, sphincterotomy during initial ERC, age, balloon sweeps on initial ERC, and the time interval between the initial and repeat ERC. None of these variables demonstrated statistical significance $(\mathrm{P}>0.05)$. A CBD stone identified during the initial ERC was the only factor that approached statistical significance with an OR of 3.1 (95\% CI 0.8 to 10.9). Among patients with a persistent bile leak on 
TABLE 1

Baseline characteristics of 80 patients who underwent endoscopic retrograde cholangiography for postcholecystectomy bile leak

\begin{tabular}{lc}
\hline Characteristic & \\
\hline Age, years, mean & 53 \\
Female sex & $51(62.6)$ \\
Cholecystectomy details & \\
Open & $14(17.5)$ \\
Laparoscopic & $46(57.5)$ \\
Laparoscopic to open conversion & $10(12.5)$ \\
Unknown & $10(12.5)$ \\
Bile leak & \\
Cystic duct & $47(58.7)$ \\
Right hepatic duct & $11(13.7)$ \\
Left hepatic duct & $2(2.5)$ \\
Common hepatic duct & $4(5)$ \\
Common bile duct & $11(13.7)$ \\
Gallbladder fossa & $5(6.2)$ \\
Common bile duct stones & $14(17.5)$ \\
Biliary stricture & $7(8.7)$ \\
Endoscopic management & \\
EBS + stent & $75(93.7)$ \\
EBS alone & $5(6.2)$ \\
Balloon sweep & $19(23.7)$ \\
\hline Da presen
\end{tabular}

Data presented as $n$ (\%) unless otherwise indicated. EBS Endoscopic biliary sphincterotomy

\section{TABLE 2}

Abnormalities at follow-up endoscopic retrograde cholangiography $(n=66)$

\begin{tabular}{lc}
\hline Persistent bile leak & $5(7.5)$ \\
Biliary stones & $4(6)$ \\
Biliary sludge & $7(10.6)$ \\
Total findings & 16 in 15 patients (22.7) \\
\hline
\end{tabular}

Data presented as $n$ (\%)

follow-up ERC, four of the five (80\%) had a cystic duct leak, four (80\%) had a laparoscopic cholecystectomy or laparoscopic converted to open cholecystectomy and only one $(20 \%)$ had a stone on the initial ERC.

\section{DISCUSSION}

Bile duct injuries are a complication of cholecystectomy, with a reported incidence of $0.8 \%$ to $1 \%$ (4). Given that more than 800,000 cholecystectomies are performed each year, this is a relatively common surgical complication that is managed using ERC. Postcholecystectomy bile leaks can be managed by various therapeutic techniques, all of which are aimed at decreasing transpapillary pressure, thereby allowing bile to flow through the path of least resistance and permitting the leak to close spontaneously. Previous studies by Cote et al (5) and Kaffes et al (6) suggested that outcomes in patients who undergo biliary stenting and sphincterotomy are equal to those who undergo stenting alone. Mavrogiannis et al (7) showed that placement of a biliary stent is more efficacious and has a lower complication rate than performing biliary sphincterotomy alone. However, biliary stents need to be removed endoscopically after clinical resolution of the bile leak.

The exact timing of resolution of bile leaks and, therefore, when biliary stents can be removed is unclear. Multiple studies have suggested four to 12 weeks after initial placement as a safe window for stent removal $(8,9)$. In the published literature, there is no uniform recommendation regarding the need for a repeat cholangiography at
No leak or stone LeakorStone present No cholangiogram

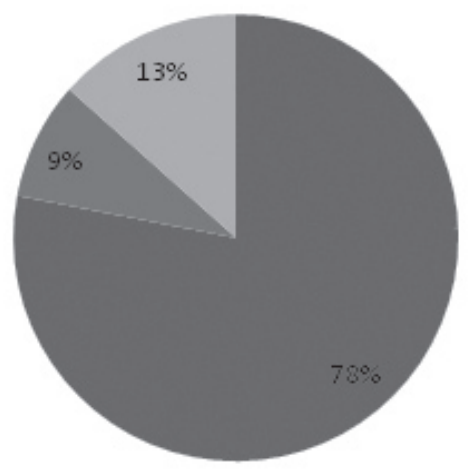

Figure 2) Findings on the repeat cholangiogram

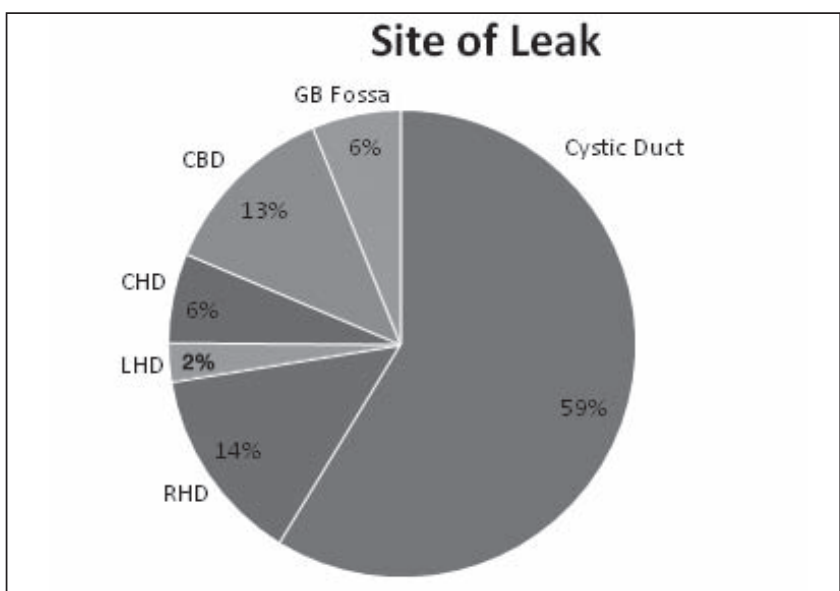

Figure 3) Site of bile leak based on the cholangiogram. CBD Common bile duct; CHD Common hepatic duct; GB Gallbladder; LHD Left hepatic duct; RHD Right hepatic duct

\section{TABLE 3}

Univariate analysis of possible factors associated with abnormal cholangiogram at follow-up endoscopic retrograde cholangiography $(E R C)(n=66)$

\begin{tabular}{|c|c|c|c|c|}
\hline Characteristic & $\begin{array}{c}\text { Abnormal } \\
\text { cholangiogram } \\
(n=15)\end{array}$ & $\begin{array}{c}\text { No } \\
\text { abnormality } \\
\text { on follow-up } \\
\text { ERC }(n=51)\end{array}$ & 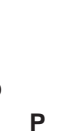 & $\begin{array}{c}\text { OR } \\
(95 \% \mathrm{Cl})\end{array}$ \\
\hline CBD stones at initial ERC & 6 & 8 & 0.073 & $3.1(0.8-10.9)$ \\
\hline \multicolumn{5}{|l|}{ Location of bile leak } \\
\hline Cystic duct & 8 & 31 & 0.60 & $0.7(0.2-2.35)$ \\
\hline Other* & 7 & 20 & & \\
\hline $\begin{array}{l}\text { Lap cholecystectomy } \\
\qquad(\mathrm{n}=39)^{\dagger}\end{array}$ & 6 & 33 & 0.004 & $\begin{array}{c}0.16 \\
(0.04-0.57)\end{array}$ \\
\hline $\begin{array}{l}\text { Biliary stricture at } \\
\text { presentation }\end{array}$ & 2 & 5 & 0.69 & $1.4(0.24-8.15)$ \\
\hline $\begin{array}{l}\text { Sphincterotomy at initial } \\
\text { ERC }\end{array}$ & 15 & 47 & 0.9 & \\
\hline Age, years, mean & 58.6 & 51 & 0.19 & \\
\hline $\begin{array}{l}\text { Balloon sweep at initial } \\
\text { ERC }\end{array}$ & 4 & 15 & 0.83 & $0.8(0.23-3.18)$ \\
\hline $\begin{array}{l}\text { Interval between ERCs, } \\
\text { weeks, mean }\end{array}$ & 7.2 & 8.8 & 0.10 & \\
\hline
\end{tabular}

${ }^{*}$ Other included leak anywhere else in the biliary tree; ${ }^{\dagger}$ Operative data were not available for eight patients. CBD Common bile duct; Lap Laparoscopic 
the time of stent removal. To date, there have been two studies published investigating this question with conflicting results. Cote et al (5) demonstrated that $27.6 \%$ of patients had some abnormality identified on repeat ERC performed at the time of biliary stent removal during the course of management of uncomplicated postcholecystectomy bile leaks. These abnormalities included a persistent bile leak in $7.5 \%$, CBD stones in $11.4 \%$ and CBD sludge alone in $8.6 \%$. Conversely, Coelho-Prabhu and Baron (10) concluded that patients with clinical resolution of uncomplicated postcholecystectomy bile leaks treated with biliary stenting do not require repeat cholangiography at the time of stent removal and can instead undergo esophagogastroduodenoscopy for this purpose. They concluded that an esophagogastroduodenoscopy with stent removal at four to six weeks is sufficient and significantly less expensive.

In our retrospective analysis of 66 patients who underwent ERC for management of a postcholecystectomy bile leak, a significant percentage $(22.7 \%)$ were found to have abnormalities on follow-up ERC performed at the time of stent removal. These abnormalities included persistent bile leak in $7.5 \%$ and stone or sludge in $16.6 \%$. These results are similar to those reported by Cote et al (5) mentioned above. More than $92 \%$ of the patients in our analysis experienced resolution of their bile leak documented during the second ERC. Our success rate of more than $90 \%$ is similar to other studies published in the endoscopic management of postcholecystectomy bile leaks using biliary stenting with or without sphincterotomy $(5,10)$.

\section{REFERENCES}

1. Morgenstern L, McGrath MF, Carroll BJ, Paz-Partlow M, Berci G. Continuing hazards of the learning curve in laparoscopic cholecystectomy. Am Surg 1995;61:914-8.

2. Pinkas H, Brady PG. Biliary leaks after laparoscopic cholecystectomy: Time to stent or time to drain. Hepatobiliary Pancreat Dis Int 2008;7:628-32.

3. Sandha GS, Bourke MJ, Haber GB, Kortan PP. Endoscopic therapy for bile leak based on a new classification: Results in 207 patients. Gastro Intest Endosc 2004;60:567-74.

4. Barkun AN, Rezieg M, Mehta SN, et al. Postcholecystectomy biliary leaks in the laparoscopic era: Risk factors, presentation, and management. McGill Gallstone Treatment Group. Gastrointest Endosc 1997;45:277-82.

5. Cote GA, Ansstas M, Shah S, et al. Findings at endoscopic retrograde cholangiopancreatography after endoscopic treatment of postcholecystectomy bile leaks. Surg Endosc 2010;24:1752-6.
It is unclear whether stones and sludge identified at the time of follow-up ERC were retained from the initial ERC or developed during the interval between procedures. Cote et al (5) performed a subgroup analysis and found that patients with CBD stones or sludge at the follow-up ERC were more likely to have had stones at their initial ERC. In our analysis, five of the 11 patients with stone or sludge on repeat ERC had a stone extracted during their initial ERC (45.5\%). Without long term follow-up evaluation, it is not possible to speculate on the significance of stones or sludge on follow-up ERCs, particularly when patients have already undergone a sphincterotomy during the initial ERC.

According to our results, although more than $90 \%$ of postcholecystectomy bile leaks resolved on repeat ERC six to eight weeks after biliary stenting, follow-up cholangiogram at the time of stent removal may reveal abnormalities that necessitate further endoscopic intervention. Until we can reliably identify patients who will undergo an abnormal ERC at the time of stent removal, we suggest performing a repeat cholangiogram on all patients who undergo ERC for postcholecystectomy bile leaks managed with biliary stent placement.

DISCLOSURES: The authors have no financial disclosures or conflicts of interest to declare. The study was approved by the Institutional Review Board at PennState Milton S Hershey Medical Center, Hershey, Pennsylvania, USA.

6. Kaffes AJ, Hourigan L, De Luca N, Byth K, Williams SJ, Bourke MJ. Impact of endoscopic intervention in 100 patients with suspected postcholecystectomy bile leak. Gastrointest Endosc 2005;61:269-75.

7. Mavrogiannis C, Liatsos C, Papanikolaou IS, Karagiannis S, Galanis P, Romanos A. Biliary stenting alone versus biliary stenting plus sphincterotomy for the treatment of post-laparoscopic cholecystectomy biliary leaks: A prospective randomized study. Eur J Gastroenterol Hepatol 2006;18:405-9.

8. Mehta SN, Pavone E, Barkun JS, Cortas GA, Barkun AN. A review of the management of post-cholecystectomy biliary leaks during the laparoscopic era. Am J Gastroenterol 1997;92:1262-7.

9. Ahmad F, Saunders RN, Lloyd GM, Lloyd DM, Robertson GS. An algorithm for the management of bile leak following laparoscopic cholecystectomy. Ann R Coll Surg Engl 2007;89:51-6.

10. Coelho-Prabhu N, Baron TH. Assessment of need for repeat ERCP during biliary stent removal after clinical resolution of postcholecystectomy bile leak. Am J Gastroenterol 2010;105:100-5. 